\title{
Impact of Atraumatic Restorative Treatment (ART) on the treatment profile in pilot government dental clinics in Tanzania Emil Namakuka Kikwilu*1, Jo Frencken ${ }^{2}$ and Jan Mulder ${ }^{3}$
}

Address: ${ }^{1}$ Department of Preventive and Community Dentistry, School of Dentistry, Muhimbili University of Health and Allied Sciences, P.O. Box 65014, Dar es Salaam, Tanzania, ${ }^{2}$ Nijmegen International Centre for Oral Health Radboud University Nijmegen Medical Centre, College of Dental Sciences, Nijmegen, The Netherlands and ${ }^{3}$ Department of Preventive and Restorative Dentistry, Radboud University Nijmegen Medical Centre, College of Dental Sciences, Nijmegen, The Netherlands

Email: Emil Namakuka Kikwilu* - ekikwilu@muhas.ac.tz; Jo Frencken - j.frencken@dent.umcn.nl; Jan Mulder - j.mulder@dent.umcn.nl

* Corresponding author

Published: 8 June 2009

BMC Oral Health 2009, 9:14 doi:10.1186/1472-6831-9-14
Received: 16 January 2009

Accepted: 8 June 2009

This article is available from: http://www.biomedcentral.com/1472-6831/9//4

(C) 2009 Kikwilu et al; licensee BioMed Central Ltd.

This is an Open Access article distributed under the terms of the Creative Commons Attribution License (http://creativecommons.org/licenses/by/2.0), which permits unrestricted use, distribution, and reproduction in any medium, provided the original work is properly cited.

\begin{abstract}
Background: The predominant mode of treatment in government dental clinics in Tanzania has been tooth extraction because the economy could not support the conventional restorative care which depends on expensive equipment, electricity and piped water systems. Atraumatic Restorative Treatment (ART) was perceived as a suitable alternative. A 3.5-year study was designed to document the changes in the treatment profiles ascribed to the systematic introduction of ART in pilot government dental clinics.
\end{abstract}

Methods: Dental practitioners who were working in 13 government dental clinics underwent a 7day ART training. Treatment record data on teeth extracted and teeth restored by the conventional and ART approaches were collected from these clinics for the three study periods. The mean percentage of ART restorations to total treatment, ART restorations to total restorations, and total restorations to total treatments rendered were computed. Differences between variables were determined by ANOVA, t-test and Chi-square.

Results: The mean percentage of ART restorations to total treatment rendered was 0.4 (SE $=0.5)$ and II.9 (SE = I.I) during the baseline and second follow-up period respectively (ANOVA mixed model; $P<0.000$ I). The mean percentage of ART restorations to total restorations rendered at baseline and $2^{\text {nd }}$ follow-up period was $8.4 \%$ and $88.9 \%$ respectively (ANOVA mixed model; $P<$ $0.000 \mathrm{I}$ ). The mean percentage of restorations to total treatment rendered at baseline and $2^{\text {nd }}$ follow-up was $3.9 \%$ and $13.0 \%$, respectively (ANOVA mixed model; $P<0.000$ I). Ninety-nine percent of patients were satisfied with ART restorations, $96.6 \%$ willing to receive ART restoration again in future, and $94.9 \%$ willing to recommend ART treatment to their close relatives.

Conclusion: ART introduction in pilot government dental clinics raised the number of teeth saved by restorative care. Countrywide introduction of the ART approach in Tanzania is recommended.

\section{Background}

By 2005, the oral healthcare in Tanzania was mainly pub-

lic and was rendered in dental clinics situated in regional and district headquarters. The predominant mode of treatment was tooth extraction [1-4] because the economy could not support conventional restorative care $[5,6]$. The 
contribution of restorative care to oral healthcare and to oral health of the population was therefore negligible [1$3,7,8]$. In addition, rural residents, who constituted $77 \%$ of the total population in Tanzania [9], had to travel long distances to urban centres to seek oral care. This unsatisfactory oral health care had existed since independence in year 1961, and a need to seek for alternative approach of managing dental caries in Tanzania became apparent. The available epidemiological data had shown that most of the carious lesions were single surface lesions located in pits and fissures of molars, which could be managed by simple restorative care [7].

Over the last two decades a preventive and restorative caries-management concept based on minimal intervention dentistry has been developed: the Atraumatic Restorative Treatment (ART) [10]. This employs an approach to treating tooth cavities that uses only hand instruments and subsequent filling of the cleaned cavity and adjacent pits and fissures with an adhesive dental material, usually a high-viscosity glass-ionomer [10]. ART does not rely on electricity and piped water systems, required for conventional restorative caries treatment, that are often unavailable in developing countries. Using ART, dentists can provide restorative care in the dental clinic even if conventional equipment is unavailable or out-of-order, and in outreach situations. Studies have indicated that six-year survival rates of single-surface ART restorations in permanent teeth of children and adolescents range from $67 \%$ to $75 \%$ which are comparable to those of similar conventional amalgam restorations [11-14]. In outreach situations in 3 Latin American countries the ART approach has proved more cost-effective than conventional dental caries management [15]. ART has also been shown to cause less dental anxiety in patients than does conventional restorative treatment $[16,17]$. Therefore, it has the potential to reduce the burden of toothache and increase the accessibility of oral care in developing countries. Consequently, WHO adopted ART in 1994 [18], the WHO Africa Office included ART in its strategic oral health policy guidelines 1999-2008 [19], and PAHO recommended the use of ART to manage dental caries in Latin-American countries [15].

Atraumatic Restorative Treatment (ART) was perceived as a suitable alternative or complementary approach to treating dental carious lesions in Tanzania. With ART, dental practitioners could restore teeth in dental clinics even if the dental equipment was out of order. In addition, they could restore teeth in outreach clinics in rural areas therefore making restorative care accessible to the majority of population in rural areas. As from 1994, ART seminars, workshops and demonstrations were conducted to different groups of dental practitioners, and in 2002 ART was incorporated into the Policy Guidelines for Oral Health
Services in Tanzania as an essential tool for managing dental caries [20]. Nevertheless, its impact on the treatment profile in different dental clinics was negligible [21].

It was not known why ART was not picking up in Tanzania despite of policy guidelines and ART seminars, workshops and demonstrations. Therefore it was decided to run a pilot project for a systematic introduction of ART in few dental clinics in order to identify facilitating and inhibiting factors for adoption of ART in government dental clinics. Lessons learnt from the pilot project were to be used to facilitate country wide dissemination of ART practice in government dental clinics in Tanzania. The aim of the present study was to assess the impact of ART introduction on the treatment profile in pilot government dental clinics and to assess patients' experiences related to it.

\section{Methods}

\section{Selection of Dental Clinics}

The inclusion requirement for participation in the pilot study was willingness of the health authority to: (1) allocate finances for purchasing glass-ionomer and ART hand instruments for use in dental clinics and (2) allow the dental practitioners to participate in a fulltime 7-day ART training course. This was aimed at overcoming potential barriers to changing professional practice related to hospital administration [22], and based on the importance of involving all stakeholders in the introduction of healthcare innovations [23]. Eventually sixteen clinics met the criteria; 3 in Dar es Salaam, 4 in Morogoro, and 9 in the Tanga Regions. A total of 32 dental practitioners were working in these 16 clinics at the start of the project, and were invited to attend an ART training course. Four of the dental practitioners were dentists, 13 were Assistant Dental Officers (ADO), and 15 were Dental Therapists (DT).

\section{The ART training course}

The course was organised in July 2005, in the Dental Therapist School in Tanga and attended by 30 practitioners in two groups of 16 and 14 participants each. Two of the 32 dental practitioners did not attend: one reported that he was denied permission; the second reported to had been caught up with other duties. It began with discussions about the outcomes of studies covering barriers to restorative care as perceived by dental patients and practitioners, and intentions of practitioners to practice ART in Tanzania [24-26]. These were followed by lectures and pre-clinical and clinical practice of ART, using a training manual [27] and publications.

\section{Supervisory visits and follow-up meetings}

A process evaluation was conducted throughout the duration of the project. Included were several checks, built into the training process to address previously documented failures in the introduction of innovations into clinical 
practice [22]. Participants were tested on the ART approach before and after the course and interactive methods of learning were used to improve understanding of the course material.

Supervisory visits to individual clinics were conducted twice yearly during the follow-up period. The first aim of these supportive visits was to observe the practitioners using ART to treat patients in their own clinic settings and help them to address any doubts regarding their clinical skills, which had been shown to be among the causes for clinical inertia [28]. The second aim was to identify and address any other barriers related to organisation of the clinics that could affect the smooth introduction of ART. The third was to check through patient records to assess the number of ART restorations that had been made within a given time. Discussions were held with hospital authorities on issues related to the introduction of ART and lobbying for continued support was done when deemed necessary.

A one-day follow-up meeting was held once at the end of each follow-up year in each of the three regions, to allow practitioners to discuss their experiences regarding the introduction of ART in their clinics. Constraints at the regional level were also discussed in these meetings.

\section{Data collection and management}

Written approval for this study was obtained from the Ethical Committee of the Muhimbili University College of Health Sciences (reference MU/RP/AEC/VOL.II/130). The treatment rendered in all pilot dental clinics was recorded on the standard patient record forms used in all clinics. These covered tooth extractions, ART restorations and conventional restorations in both primary and permanent teeth. Only data from 13 pilot dental clinics in which the dental practitioners who attended an ART training course worked throughout the follow-up period were included in this analysis. Three pilot dental clinics had incomplete data because the dental practitioners who had attended an ART training course had been transferred to other clinics. Patients' views on the ART approach were collected during the $2^{\text {nd }}$ follow-up period, using the structured questionnaire (Table 1).

The patient questionnaire data and the monthly summary of dental data for the total 31-month post-ART-training follow-up period and the 12-month pre-ART-training

Table I: Distribution of patients by their responses to questions on how they had experienced being treated using the ART approach

\begin{tabular}{|c|c|c|}
\hline Question & Number & Percent \\
\hline \multicolumn{3}{|l|}{ Gender } \\
\hline - Men & 111 & 42.4 \\
\hline - Women & 151 & 57.6 \\
\hline \multicolumn{3}{|c|}{ How did you feel during ART procedure? } \\
\hline - I felt no pain & 159 & 60.7 \\
\hline - I felt slight/or pain & 103 & 39.3 \\
\hline \multicolumn{3}{|c|}{ How satisfied are you with the ART treatment } \\
\hline - Satisfied & 260 & 99.2 \\
\hline - Dissatisfied & 2 & 0.8 \\
\hline \multicolumn{3}{|c|}{ Are you willing to get the same treatment next time if need arises } \\
\hline - Yes & 258 & 98.9 \\
\hline - No & 3 & 1.1 \\
\hline \multicolumn{3}{|c|}{ Are you willing to recommend the same treatment to your family member or friend } \\
\hline - Yes & 252 & 97.3 \\
\hline - No & 7 & 2.7 \\
\hline \multicolumn{3}{|c|}{ *Comparing with tooth extraction, ART is a better treatment } \\
\hline - Agree & 200 & 96.6 \\
\hline - Disagree & 7 & 3.4 \\
\hline \multicolumn{3}{|c|}{ \$Comparing with restoration using a drill, ART is a better approach } \\
\hline - Agree & 111 & 94.9 \\
\hline - Disagree & 6 & 5.1 \\
\hline
\end{tabular}

* Only those who had tooth extraction before responded to this question.

$\$$ Only patients who had received a traditional restoration before responded to this question 
period were entered into two data bases, exported into SAS software version 11 and analysed by an oral statistician.

\section{Construction of variables}

The treatments provided included extractions, restorations using conventional rotary equipment and restorations using the ART approach. A new dependent variable, total treatment, was constructed: the sum of extracted teeth + conventionally restored teeth + ART restored teeth. Other dependent variables were: pct-ART-all, the percentage of ART restorations to the total treatment rendered; ART-fraction, the percentage of ART to total teeth restored (ART restorations + conventional restorations); and pcttotalrest, the percentage of total restorations to total treatments rendered.

The independent variables were region (Dar es Salaam, Morogoro, Tanga), clinic location (rural, urban) and period of study (baseline, $1^{\text {st }}$ follow-up, $2^{\text {nd }}$ follow-up). Baseline was the 12 -months pre-ART-training. The $1^{\text {st }}$ follow-up period was the first 21-months post-ART-training, when all practitioners had returned to their clinics with a set of ART hand instruments and one pack of glass-ionomer, after completing the ART training course. Difficulties in obtaining additional supplies of glass-ionomer and ART hand instruments characterised this period. The $2^{\text {nd }}$ follow-up period covered the last 10-months post-ART-training and was characterised by adequate supplies of glassionomer and ART hand instruments.

The responses to the questions regarding patient's views on ART treatment that had more than 2 options (Table 1) were dichotomized as follows: "I felt pain" and "I felt slight pain" were combined into "I felt pain"; "no pain at all" became "I felt no pain"; "satisfied" and "slightly satisfied" were combined into "satisfied", while "slightly dissatisfied" and "dissatisfied" were combined into "dissatisfied";. "agree completely" and "slightly agree" were combined into "agree"', "slightly disagree" and "disagree completely" were combined into "disagree".

\section{Statistical analysis}

The mean percentages for pct-ART-all, ART-fraction, and pct-totalrest were calculated. Analysis of Variance was performed to test for statistical differences between dependent and independent variables, whereas the t-test was applied to test for differences between the variables. Statistical significance was set at $\mathrm{p}<0.05$. Data from three clinics were incomplete and were excluded from analysis. The Chi-square test was applied to detect associations between variables related to patients' views on ART.

\section{Results}

Table 1 summarises the responses from 262 patients to questions on how they had experienced treatment with ART. Sixty percent felt no pain during the ART procedure of cleaning and restoring tooth cavities without local anaesthesia, while 99\% were satisfied after having received an ART restoration.

Table 2 summarises the number of teeth treated in 13 pilot dental clinics during the period of study. A total of 96,719 teeth, of which $89 \%$ were permanent teeth, were treated during the 43-month study period. The monthly mean number of conventional restorations dropped from

Table 2: Total and monthly mean number and standard error (SE) of teeth treated in 13 dental clinics by period of study

\begin{tabular}{|c|c|c|c|}
\hline \multirow[b]{2}{*}{ Total and monthly mean number of teeth treated } & \multicolumn{3}{|c|}{ Period of study* } \\
\hline & Baseline & Ist follow-up & $2^{\text {nd }}$ follow-up \\
\hline \multicolumn{4}{|l|}{ Extractions } \\
\hline - Total & 21,864 & 44,050 & 23,762 \\
\hline - Mean & I,822 & 2,097 & 2,376 \\
\hline - Standard Error & 41.0 & 46.0 & 52.5 \\
\hline \multicolumn{4}{|l|}{ Conventional restorations } \\
\hline - Total & 786 & 856 & 332 \\
\hline - Mean & 65 & 40 & 33 \\
\hline - Standard error & 3.1 & 3.0 & 2.5 \\
\hline \multicolumn{4}{|l|}{ ART restorations } \\
\hline - Total & 190 & 2,690 & 2,189 \\
\hline - Mean & 16 & 128 & 219 \\
\hline - Standard error & 4.5 & 9.9 & 10.4 \\
\hline
\end{tabular}

*Baseline period = I year period before ART training course;

Ist follow-up period $=21$ months after ART training course, characterised by interruption in supplies;

$2^{\text {nd }}$ follow-up period $=10$ months of adequate supplies. 
65 at baseline to 33 at the $2^{\text {nd }}$ follow-up period. The monthly mean number of ART restorations, on the other hand, increased from 16 during baseline to 219 during the $2^{\text {nd }}$ follow-up period.

The mean percentage of ART restorations to total treatment rendered in 13 pilot dental clinics by region, clinic location and period of study is shown in Table 3. The overall mean percentage of ART restorations to total treatment rendered was $0.4(\mathrm{SE}=0.5)$ during the baseline, and $11.9(\mathrm{SE}=1.1)$ during the second follow-up period. The differences were statistically significant in both regions and clinic locations (ANOVA mixed model; $P<0.001$ ).

Table 4 summarises the mean percentage of ART restorations to total restorations in 13 dental clinics by region, clinic location and period of study. The overall mean percentage of ART restorations to total restorations rendered was $8.4(\mathrm{SE}=2.2)$ during the baseline, and $88.9(\mathrm{SE}=1.8)$ during the second follow-up period. The differences were statistically significant in both regions and clinic locations (ANOVA mixed model; $P=0.001$ ).

The mean percentage of the total restorations to total treatment rendered in 13 dental clinics by region, clinic location and period of study is summarized in Table 5 . The overall mean percentage of all restorations to total treatment rendered was 3.9 ( $\mathrm{SE}=0.4$ ) during the baseline, and $13.0(\mathrm{SE}=1.1)$ during the second follow-up period. The differences were statistically significant in both regions and clinic locations (ANOVA mixed model; $P<$ $0.001)$.

\section{Discussion}

The current ART pilot project was undertaken following negligible impact of ART to restorative care in Tanzania

Table 3: Mean percentage and Standard Error (SE) of ART restorations to total treatment rendered in 13 dental clinics by region, clinic location and period of study

\begin{tabular}{|c|c|c|c|}
\hline & \multicolumn{3}{|c|}{ Period of study } \\
\hline & Baseline & |st follow-up & $2^{\text {nd }}$ follow-up \\
\hline & Mean (SE) & Mean (SE) & Mean (SE) \\
\hline \multicolumn{4}{|l|}{ Region } \\
\hline Dar es Salaam & $2.0(0.5)^{a}$ & $3.1(0.5) b$ & $6.1(0.6)^{c}$ \\
\hline Morogoro & $0.0^{d}$ & $9.0(0.8)^{e}$ & $1 \mathrm{I} .4(1.0)^{\mathrm{f}}$ \\
\hline Tanga & $0.1(0.1)^{\mathrm{g}}$ & $7.2(0.8)^{\mathrm{h}}$ & I $3.8(1.8)^{i}$ \\
\hline Total & $0.4(0.1)$ & $7.1(0.5)$ & $11.9(1.1)$ \\
\hline \multicolumn{4}{|l|}{ Clinic location } \\
\hline Rural & $0.0 \mathrm{i}$ & $8.2(0.7)^{\mathrm{k}}$ & $|4.|(1.6)^{\mid}$ \\
\hline Urban & $0.9(0.3)^{m}$ & $5.4(0.8)^{n}$ & $8.3(0.9)^{\circ}$ \\
\hline Total & $0.4(0.1)$ & $7.1(0.5)$ & $11.9(1.1)$ \\
\hline
\end{tabular}

ANOVA mixed model: no, ci, lo $P<0.05 ; \mathrm{mn} P<0.00$; de, df, gh, fh, hi, jk, jl, kl, mo $P<0.0001$
Table 4: Mean percentage and Standard Error (SE) of ART restorations to total restorations in 13 dental clinics by region, clinic location and period of study

\begin{tabular}{|c|c|c|c|}
\hline & \multicolumn{3}{|c|}{ Period of study period } \\
\hline & Baseline & | st follow-up & $2^{\text {nd }}$ follow-up \\
\hline & Mean (SE) & Mean (SE) & Mean (SE) \\
\hline \multicolumn{4}{|l|}{ Region } \\
\hline Dar es Salaam & $33.2(6.9)^{a}$ & $53.5(4.7)^{b}$ & $76.2(5.4)^{c}$ \\
\hline Morogoro & $0.0 \mathrm{~d}$ & $83.8(2.7)$ e & $92.3(2.7)^{f}$ \\
\hline Tanga & $1.6(1.6) \mathrm{g}$ & $76.9(3.4)^{h}$ & $90.8(2.2) \mathrm{i}$ \\
\hline Total & $8.4(2.2)$ & $75.3(2.2)$ & $88.9(1.8)$ \\
\hline \multicolumn{4}{|l|}{ Clinic location } \\
\hline Rural & $0.0 \mathrm{j}$ & $81.9(2.2)^{k}$ & 91.1 (2.0)' \\
\hline Urban & $21.2(5.0) \mathrm{m}$ & $64.3(4.3)^{n}$ & $85.2(3.2)^{\circ}$ \\
\hline Total & $8.4(2.2)$ & $75.3(2.2)$ & $88.9(1.8)$ \\
\hline
\end{tabular}

ANOVA mixed model kl $P=0.03$; mn, ab, bc, $P<0.01$; ac, de, df, gh, gi, jk, jl, mn, mo, no $P<0.0001$

despite of the recommendations of WHO Africa Region [19] and of the Ministry of Health and Social Welfare in Tanzania [20] for its use. Both WHO and the Ministry of Health in Tanzania were convinced that ART would improve the management of dental caries; from mainly tooth extractions to more restorative care. To increase chances for success, the implementation of the ART pilot project was undertaken after investigating and solving the potential barriers to restorative care among dental practitioners and patients and ascertaining the willingness of dental practitioners to practice ART [24-26]. In addition, a built-in process evaluation was instituted, to identify and address any other barriers that might have arisen in the implementation process. The check list of important issues to address in the process evaluation was obtained

Table 5: Mean percentage and standard error (SE) of the total number of restorations to all treatments rendered in 13 dental clinics by region, clinic location and period of study

\begin{tabular}{|c|c|c|c|}
\hline & \multicolumn{3}{|c|}{ Period of study } \\
\hline & Baseline & Ist follow-up & $2^{\text {nd }}$ follow-up \\
\hline & Mean (SE) & Mean (SE) & Mean (SE) \\
\hline \multicolumn{4}{|l|}{ Region } \\
\hline Dar es Salaam & $4.3(0.5)^{a}$ & $4.9(0.6)^{b}$ & $7.7(0.4)^{c}$ \\
\hline Morogoro & $1.9(0.4)^{d}$ & $11.0(0.9) \mathrm{e}$ & $11.9(0.9)^{f}$ \\
\hline Tanga & $5.0(0.7) \mathrm{g}$ & $8.5(0.9)^{h}$ & $15.3(1.9) \mathrm{i}$ \\
\hline Total & $3.9(0.4)$ & $8.7(0.6)$ & $13.0(1.1)$ \\
\hline \multicolumn{4}{|l|}{ Clinic location } \\
\hline Rural & $4.7(0.6)^{\mathrm{i}}$ & $10.1(0.8)^{k}$ & $15.5(1.6)^{\prime}$ \\
\hline Urban & $2.7(0.4)^{\mathrm{m}}$ & $6.5(0.8)^{n}$ & $9.2(0.8)^{\circ}$ \\
\hline Total & $3.9(0.4)$ & $8.7(0.6)$ & $13.0(1.1)$ \\
\hline
\end{tabular}

ANOVA mixed model no, lo $P<0.05$; $\mathrm{mn}<0.0 \mathrm{l}$; gh $P<0.00$ I; de, df, hi, gijk, $\mathrm{jl}, \mathrm{kl}, \mathrm{mo} P<0.000 \mathrm{l}$ 
from the extensive literature review of interventions that have been shown to be consistently effective [29-31], potential barriers to changing clinical practice [32,33], and what works best in developing countries when you want to introduce evidence into practice [34]. This was the first time that the ART approach was introduced into a national oral healthcare system in a systematic manner. Therefore experiences of interventions in health care other than those related to introduction of ART in oral health care were used.

Studies to evaluate the effect of an intervention require a control group. As ART required training in order to practice it, dental practitioners who were not trained in ART could not be expected to practice it, which would have rendered comparison between experimental and control groups meaningless. Therefore, a control group was not included in the present study. The treatment data collected one year before the ART training course were considered the control data for subsequent comparison with the data collected during the follow-up periods. Nevertheless, treatment data from comparable non-pilot clinics were compared with those of the pilot clinics, showing close similarity in number of attendances and number of extractions but in lower number of restorations provided over the study period. Therefore, the increased effect of ART restorations relative to total treatment rendered in pilot clinics is a valid outcome.

The current pilot project did not use the mass media to advocate the availability of the ART approach in pilot clinics; for fear that some clinics could lack the capacity to handle all patients who might demand this service because of inexperience in ART practice. Nevertheless, patients who were treated through the ART approach spread the news to their relatives and neighbours. Therefore, the availability of ART approach became known by increasing numbers of patients who came to pilot clinics demanding the service. In view of the experience gained by practitioners in three years, advertising to the community might now be considered.

The finding that the contribution of ART restorations to total treatment rendered during the second follow-up period, which was accompanied by an adequate supply of glass-ionomer and ART hand instruments, was higher than during the first follow-up period shows the importance of government-ensured availability of a constant supply of these essential items. The contribution of ART restorations to total treatment was higher in the present study than in a provincial oral health service system using ART in South Africa [35]. We ascribe the higher success rate obtained in Tanzania to the structured approach used in introducing ART in Tanzania.
The finding that $60 \%$ of patients who were treated through the ART approach reported no pain is in line with the reported $68 \%$ among children in a remote village in Mexico [36] and among adolescents in Egypt (63\%) [37]. Nevertheless, it was lower than the $80.6 \%$ reported among adolescents in Pakistan [16]. These findings correlate well with the finding that the ART restorative approach provokes less anxiety in patients during treatment than the conventional approach does [17].

The reduction in the mean number of conventional restorations during the evaluation period indicates that practitioners favoured ART over conventional restorations. The finding that the majority of the patients were satisfied with the ART approach, and that most of patients who had previously received conventional restorative care preferred ART to the conventional approach, showed patients' acceptance of ART. These two outcomes are important to oral health in Tanzania because restorative care can now be undertaken at lower cost, through wide use of ART instead of conventional restorative care using amalgam, which has been shown to be more expensive than ART [15]. Together with preventive and promotional activities, oral health can now be adequately provided to children through the school education system. The systematic approach taken was new and deserves to be applied in developing countries with similar inadequate oral healthcare services as in Tanzania.

\section{Conclusion}

The introduction of ART in pilot government dental clinics raised the number of teeth that were saved by restorative care, which otherwise could have been extracted. Patients appreciated the ART approach. Introduction of ART to other regions in Tanzania, and to developing countries, under close monitoring, is recommended.

\section{Competing interests}

The authors declare that they have no competing interests.

\section{Authors' contributions}

EK participated in conception and design of the study, training practitioners, follow-up supervision, and data collection and drafting the manuscript. JF participated in conception and design of the study, training practitioners, guidance in the management of the pilot study, review of manuscript. JM participated in the study design, statistical analysis and reviewed the manuscript. All authors read and approved the final manuscript.

\section{Acknowledgements}

We thank the dental practitioners in charge of the clinics for enthusiastically participating in the study. The first author is grateful to the Principal of MUHAS for the opportunity given to carry out this investigation. We are 
grateful to Cordaid, the Netherlands, for financing the ART course and to 3MESPE, Germany, for donating the glass-ionomer.

\section{References}

I. Baelum $\mathrm{V}$, Fejerskov $\mathrm{O}$ : Tooth loss as related to dental caries and periodontal breakdown in adult Tanzanians. Community Dent Oral Epidemiol 1986, I 4:353-357.

2. van Palenstein Helderman WH, Nathoo ZA: Dental treatment demands among patients in Tanzania. Community Dent Oral Epidemiol 1990, 18:85-87.

3. Mosha HJ, Lema PA: Reasons for tooth extraction among Tanzanians. East Afr Med J 1991, 68:10-14.

4. Sarita PT, Witter DJ, Kreulen CM, Matee MI, van't Hof MA, Creugers $\mathrm{N}$ : Decayed/missing/filled teeth and shortened dental arches in Tanzanian adults. Int J Prosthodont 2004, I 7:224-230.

5. Central Oral Health Unit: Annual regional dental services reports. Central Oral Health Unit, Ministry of Health and Social Welfare, United Republic of Tanzania, Dar es Salaam; 2005: I I-I 3.

6. Central Oral Health Unit: Plan for rehabilitation and equipping dental clinics at all hospital levels in Tanzania. Central Ora Health Unit, Ministry of Health and Social Welfare, United Republic of Tanzania, Dar es Salaam; 2001:26-28.

7. Mosha HJ, Ngilisho LA, Nkwera H, Scheutz F, Poulsen S: Oral health status and treatment needs in different age groups in two regions of Tanzania. Community Dent Oral Epidemiol 1994 22:307-310

8. Frencken JE, van't Hof MA, Truin GJ, Lembariti BS, König KG: Cohort effects in the prevalence of caries in child populations in Tanzania. J Dent Res 1989, 68: I777- 1780

9. Tanzania National census, 2002 [http://www.tanzania.go.tz/cen susdb/ageSexMainlandSingleYears.asp]

10. Frencken JE, Pilot T, Songpaisan Y, Phantumvanit P: Atraumatic Restorative Treatment (ART): rationale, technique, and development. J Public Health Dent 1996, 56: I 35- I 40.

II. Mandari GJ, Frencken JE, van't Hof MA: Six-year success rates of occlusal amalgam and glass-ionomer restorations placed using three minimal intervention approaches. Caries Res 2003. 37:246-253.

12. Frencken JE, Taifour D, van't Hof MA: Survival of ART and amalgam restorations in permanent teeth of children after 6.3 years. I Dent Res 2006, 85:622-626.

13. Lo EC, Holmgren CJ, Hu D, van Palenstein Helderman W: Six-year follow up of atraumatic restorative treatment restorations placed in Chinese school children. Community Dent Oral Epidemiol 2007, 35:387-392.

14. Prakki A, Nunes MC, Cefaly DF, Lauris JR, Navarro MF: Six-year evaluation of the atraumatic restorative treatment approach in permanent-tooth Class III restorations. J Adhes Dent 2008, 10:233-237.

15. PAHO: Oral health of low income children. Procedures for Atraumatic Restorative Treatment. In Final Report Pan American Health Organization, Washington DC; 2006.

16. Rahimtoola S, van Amerongen E, Maher $\mathrm{R}$, Groen H: Pain related to different ways of minimal intervention in the treatment of small caries lesions. I Dent Child 2000, 67:123-127.

17. Mickenautsch S, Frencken JE, van't Hof MA: Atraumatic Restorative Treatment and dental anxiety in outpatients attending public oral health clinics in South Africa. I Public Health Dent 2007, 67:179-184

18. WHO: Revolutionary new procedure for treating dental caries. Geneva: World Health Day Press Release WHO/28, World Health Organization; 1994.

19. WHO Regional Office for Africa: Oral health in the African Region. A regional strategy 1999-2008. World Health Organization Regional Office for Africa, Harare; 2000.

20. Ministry of Health and Social Welfare: Policy Guidelines for Ora Health Services in Tanzania 2002. Ministry of Health and Social Welfare. Central Oral Health Unit, Dar es Salaam; 2002.

21. Mandari G], Matee Ml: Atraumatic Restorative Treatment (ART): the Tanzanian experience. Int Dent J 2006, 56:7I-76.

22. Kao RT: The challenges of transferring evidence-based dentistry into practice. J Evid Based Dent Pract 2006, 6:।25-I28.

23. Craig N, McGregor S, Drummond N, Fischbacher M, Iliffe S: Factors affecting the shift towards a 'primary care-led' NHS: a quali- tative study. National Health Service. Br J Gen Pract 2002, 52:895-900

24. Kikwilu EN, Frencken JE, Mulder J, Masalu JR: Barriers to restorative care as perceived by dental patients attending government hospitals in Tanzania. Community Dent Oral Epidemiol 2009, 37:35-44.

25. Kikwilu EN, Frencken JE, Mulder J, Masalu JR: Barriers to restorative care as perceived by dental practitioners in Tanzania. Community Dent Health 2009 in press.

26. Kikwilu EN, Frencken JE, Mulder J, Masalu JR: Dental practitioners' attitudes, subjective norms and intentions to practice Atraumatic Restorative Treatment (ART) in Tanzania. J Appl Oral Sci 2009, 17:97-102.

27. Frencken J, Phantumvanit P, Pilot T, Songpaisan $Y$, van Amerongen E: Manual for the Atraumatic Restorative Treatment approach to control dental caries. WHO Collaborating Centre for Oral Health Services Research, Groningen; 1997.

28. Kai J, Beavan J, Faull C, Dodson L, Gill P, Beighton A: Professional uncertainty and disempowerment responding to ethnic diversity in health care. A qualitative study. PLoS Med 2007. 4:e323.

29. Oxman AD, Thomson MA: No magic bullets: A systematic review of 102 trials of interventions to improve professional practice. Canadian Med Assoc J 1995, I53:|423-|43I.

30. Effective Health Care: Bulletin on the Effectiveness of health services interventions for decision makers. Volume 5 . The Royal Society of Medicine Press Limited, University of New York; 1999:1-16.

31. MacGlone P, Watt R, Sheiham A: Evidence-based dentistry: an overview of the challenges in changing professional practice. $\mathrm{Br}$ Dent / 200I, I 90:636-639.

32. Clarkson JE: Getting research into clinical practice - barriers and solutions. Caries Res 2004, 38:321-324

33. Rindal DB, Rush WA, Boyle RG: Clinical inertia in dentistry: A review of the phenomenon. J Contemp Dent Pract 2008, 9:113-121.

34. Siddiqi K, Newell J, Robinson M: Getting evidence into practice: what works in developing countries? Int J Qual Health Care 2005, I 7:447-454.

35. Mickenautsch S: The impact of the ART approach on the treatment pattern in a public oral health service in South Africa. In Ph.D thesis Nijmegen: Radboud University; 2007.

36. Lopex N, Simpser-Rafalin S, Berthold P: Atraumatic restorative treatment for prevention and treatment of caries in an underserved community. Am J Public Health 2005, 95:I338-I 339.

37. Farag A, Frencken JE: Acceptance and discomfort from Atraumatic Restorative Treatment in secondary school students in Egypt. Med Princ Pract 2009, I 7:26-30.

\section{Pre-publication history}

The pre-publication history for this paper can be accessed here:

http://www.biomedcentral.com/1472-6831/9/14/prepub

Publish with Biomed Central and every scientist can read your work free of charge

"BioMed Central will be the most significant development for disseminating the results of biomedical research in our lifetime. "

Sir Paul Nurse, Cancer Research UK

Your research papers will be:

- available free of charge to the entire biomedical community

- peer reviewed and published immediately upon acceptance

- cited in PubMed and archived on PubMed Centra

- yours - you keep the copyright 